\title{
AVALIAÇÃO DA INFLUÊNCIA DA RESOLUÇÃO DO MODELO DIGITAL DE TERRENO NA MODELAGEM NUMÉRICA DE ESCORREGAMENTOS E FLUXO DE DETRITOS
}

\section{Evaluation of the influence of digital terrain model resolution on the numerical modeling of shallow landslides and debris flow}

\author{
Alessandro Gustavo Franck \\ Graduando do curso de Engenharia Hídrica, UFRGS \\ alessandrof17@hotmail.com \\ Joana Souza de Gusmão \\ Mestranda em Geografia, Instituto de Geociências, UFRJ \\ joanasgusmao@gmail.com \\ Masato Kobiyama \\ Professor, Instituto de Pesquisas Hidráulicas, UFRGS \\ masato.kobiyama@ufrgs.br
}

\begin{abstract}
RESUMO: Escorregamentos e fluxos de detritos no Brasil são fenômenos naturais desencadeados por eventos extremos de chuva. Ao longo das últimas décadas, um grande número de eventos de diferentes magnitudes vem sendo registrados em diferentes regiões do Brasil. Como uma importante medida preventiva, frequentemente são elaborados mapas de áreas suscetíveis a movimentos de massa. Modelos computacionais têm sido amplamente utilizados, e são desenvolvidos a partir de Modelos Digitais de Terreno (MDT). Desta forma o objetivo do presente trabalho foi avaliar a influência da resolução de um MDT sobre o desempenho dos modelos SHALSTAB e Kanako-2D por meio da aplicação dos mesmos a um bairro no município de Igrejinha/RS. Foi utilizado um MDT de $2,5 \mathrm{~m}$ o qual foi posteriormente reamostrado para as resoluções de $5 \mathrm{~m}, 10 \mathrm{~m}, 25 \mathrm{~m}$ e $50 \mathrm{~m}$. Os resultados demonstraram uma alta influência da resolução, principalmente em pequena escala de análise e para as resoluções de $25 \mathrm{~m}$ e $50 \mathrm{~m}$. Também mostraram que para a escala utilizada no presente estudo, a resolução mínima de um MDT deve ser de $10 \mathrm{~m}$.
\end{abstract}

Palavras-chave: Kanako-2D; SHALSTAB; Movimentos de massa.

\begin{abstract}
Landslides and debris flows in Brazil are natural phenomena triggered by extreme rainfall events. Over the last decades, a large number of events of various magnitudes have been recorded in different regions of Brazil. As an important preventive measure, maps of areas susceptible to mass movement are frequently elaborated. Computational models have been widely used, and are developed from Digital Terrain Models (DTM). Therefore, the objective of the present work was to evaluate the influence of the DTM resolution on the performance of the SHALSTAB and Kanako-2D models by applying them to a neighborhood in the municipality of Igrejinha/RS. A $2.5 \mathrm{~m}$ DTM was used, which was later resampled for resolutions of $5 \mathrm{~m}, 10 \mathrm{~m}, 25 \mathrm{~m}$ and $50 \mathrm{~m}$. The results demonstrated a strong influence of the resolution, mainly in small scale of analysis and for the resolutions of $25 \mathrm{~m}$ and $50 \mathrm{~m}$. They also showed that for such a mapping, the minimum resolution of a DTM must be $10 \mathrm{~m}$.
\end{abstract}

Keywords: Kanako-2D; SHALSTAB; Mass movement. 
AVALIAÇÃo DA INFLUÊNCIA DA RESOLUÇÃO DO MODELO DIGITAL DE TERRENO NA MODELAGEM NUMÉRICA DE ESCORREGAMENTOS E FLUXO DE DETRITOS

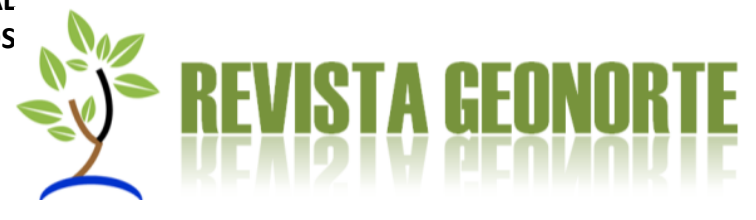

\section{INTRODUÇÃO}

Os eventos extremos de chuva têm se tornado cada vez mais frequentes em diversas regiões brasileiras, acarretando inúmeros fenômenos naturais catastróficos, como escorregamentos e fluxos de detritos (MARENGO, 2009). No Brasil os desastres naturais, causados por esses fenômenos, concentram-se, principalmente, em regiões montanhosas (KOBIYAMA et al., 2018, 2019), onde uma grande magnitude de eventos foi registrada ao longo dos últimos anos nos estados de Santa Catarina em 2008 (GOERL et al., 2009) e em 2020 (MICHEL et al., 2021b), Rio de Janeiro em 2011 (COELHO NETTO et al., 2011) e Rio Grande do Sul em 2017 (PAIXÃO et al., 2018) e em 2020 (PAIXÃO et al., 2021a). Dessa forma, como subsídio à gestão e ao planejamento territorial e ambiental, são essenciais os mapeamentos de áreas suscetíveis a esses fenômenos.

Dado esse cenário, diversas metodologias, como a combinação de modelos computacionais e modelos matemáticos, têm sido desenvolvidas no mundo e aplicadas no mapeamento de áreas suscetíveis a movimentos de massa. Por exemplo, Gomes et al. (2013) aplicaram o Shallow Landsliding Stability Model SHALSTAB (MONTGOMERY e DIETRICH, 1994) e o FLO-2D (O'BRIEN et al., 1993) para o município de Rio de Janeiro/RJ. A combinação dos modelos SHALSTAB e Kanako-2D (NAKATANI et al., 2008) foi aplicada pela primeira vez em um estudo do município de Porto Alegre/RS, por Michel e Kobiyama (2016). Após esse estudo, tal combinação foi aplicada ao estudo no município de Alto Feliz/RS (KOBIYAMA e MICHEL, 2019). Esses estudos de caso demonstram uma boa aplicabilidade dessa combinação para mapeamento de áreas susceptíveis a movimentos de massa. Aqui se salienta que para simulações destes fenômenos, são utilizados parâmetros geotécnicos, geomorfológicos e hidrológicos da área de estudo.

Muitos trabalhos apontam as condicionantes geomorfológicas - como a declividade, a forma e a orientação da encosta, como essenciais nas análises de estabilidade (DIETRICH e MONTGOMERY, 1998; BORGA et al., 2002; GOMES et al., 2004; SILVA et al., 2016). Através de um Modelo Digital de Terreno (MDT), em formato raster, são obtidas as variáveis topográficas tais como declividade e área de contribuição. A forma da encosta (divergente, plana ou convergente) orienta as linhas de drenagem e faz com que a encosta apresente diferentes padrões de saturação. Desta maneira, encostas convergentes têm maior probabilidade de ocorrência de escorregamentos devido ao escoamento subsuperficial com convergência (TSUKAMOTO e MINEMATSU, 1987). A qualidade destas informações depende da escala do mapeamento básico utilizado. Michel et al. (2021a) ressaltaram a importância da estimativa da declividade, afirmando que os MDTs podem apresentar deficiências na representação desse parâmetro devido a sua elaboração a partir de mapas com um tamanho de pixel inadequado.

Diversos trabalhos demonstraram a influência da resolução do MDT na modelagem numérica, por exemplo, Guimarães et al. (2004) avaliaram a influência das escalas de 1:10.000 e 1:50.000 na modelagem de áreas suscetíveis a escorregamentos com 
AVALIAÇÃo DA INFLUÊNCIA DA RESOLUÇÃO DO MODELO DIGITAL DE TERRENO NA MODELAGEM NUMÉRICA DE ESCORREGAMENTOS E FLUXO DE DETRITOS

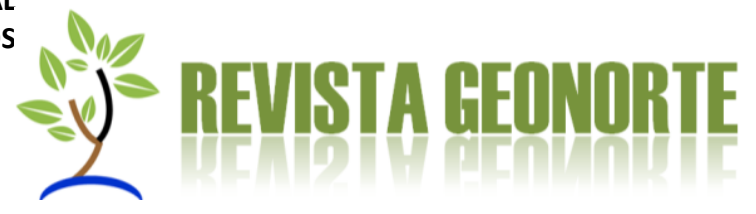

o SHALSTAB, e Tran et al. (2017) utilizaram o TRIGRS (BAUM et al., 2008) para avaliar 5 diferentes resoluções. Tais influências do MDT devem ser dependentes dos fenômenos naturais e também dos tipos de modelos computacionais (softwares) utilizados. Assim, é necessário verifica-las em cada caso.

Visto que a resolução do MDT pode exercer forte influência no processo de modelagem, o objetivo do presente trabalho foi realizar uma análise do efeito de diferentes tamanhos de pixel no mapeamento de áreas suscetíveis a movimentos de massa (escorregamentos translacionais e fluxos de detritos), através do uso conjunto dos modelos SHALSTAB e Kanako-2D, para uma localidade dentro do município de Igrejinha/RS, e uma comparação na classificação dessas áreas susceptíveis.

\section{MATERIAIS E MÉTODOS}

\section{Área de estudo}

O local de estudo é dentro do município de Igrejinha, localizado na região nordeste do estado do Rio Grande do Sul. Este município faz parte da bacia hidrográfica do Rio dos Sinos, mais precisamente na sub-bacia do Paranhana (Figura 1), e possui uma população de 31.660 habitantes, distribuída em uma área de $136,8 \mathrm{~km}^{2}$, o que resulta em uma densidade populacional de 234,4 hab. $\mathrm{km}^{-2}$ (IBGE, 2011).

Segundo a classificação de Köppen-Geiger, apresenta um clima subtropical úmido (Cfa) e registra valores de precipitação da ordem de $1.650 \mathrm{~mm} . \mathrm{ano}^{-1}$, dividida entre 130 a 150 dias de chuva, sendo os meses mais chuvosos no período de junho a outubro (ROSSATO, 2011; BRUBACHER et al., 2012). Nesse município encontra-se uma grande amplitude altimétrica, variando de 20 até $770 \mathrm{~m}$, com a zona urbana localizada nas áreas mais baixas (20 a 100 m). 


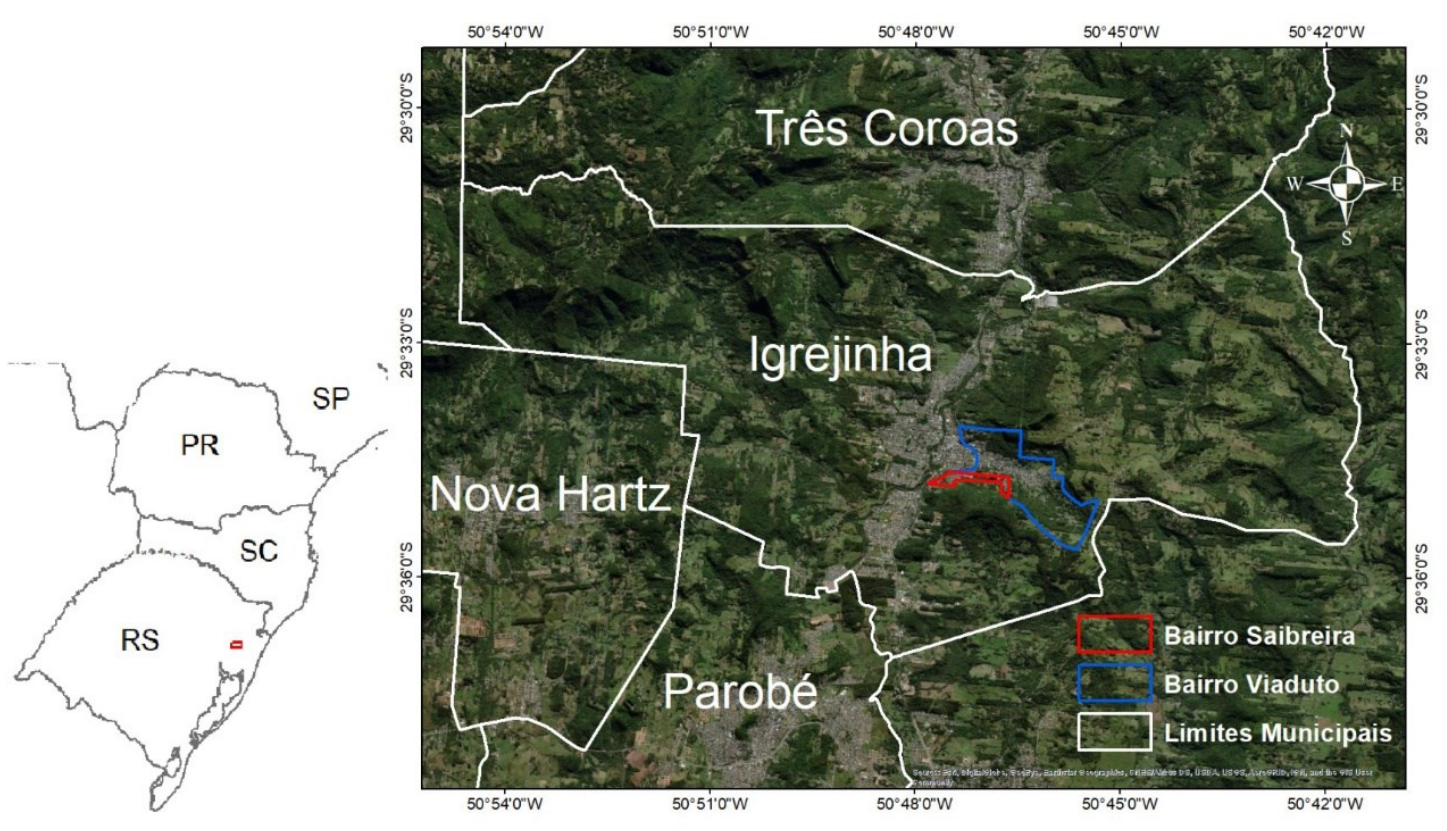

Figura 1. Localização do município de lgrejinha-RS. Fonte: Autores.

O município de Igrejinha possui registros de diversos eventos de inundações e escorregamentos (AZAMBUJA, 2011; MARTINS, 2013; GOERL et al., 2017). No decorrer de sua história, o município sofreu inundações de pequenas e grandes proporções, geralmente na área central da cidade que fica inundada pelo rio Paranhana. Além dos problemas com inundações, na área central do município, há também um histórico de desastres com movimentos de massa. A Figura 2 mostra o cenário pós-evento que ocorreu no bairro Saibreira em 23 de abril de 2011, com sete vítimas fatais (CEPED-RS/UFRGS, 2014). O presente estudo foi realizado no bairro Viaduto em uma região com aproximadamente $03 \mathrm{~km}^{2}$, próximo ao bairro Saibreira. 
AVALIAÇÃO DA INFLUÊNCIA DA RESOLUÇÃO DO MODELO DIGITAL DE TERRENO NA MODELAGEM NUMÉRICA DE ESCORREGAMENTOS E FLUXO DE DETRITOS
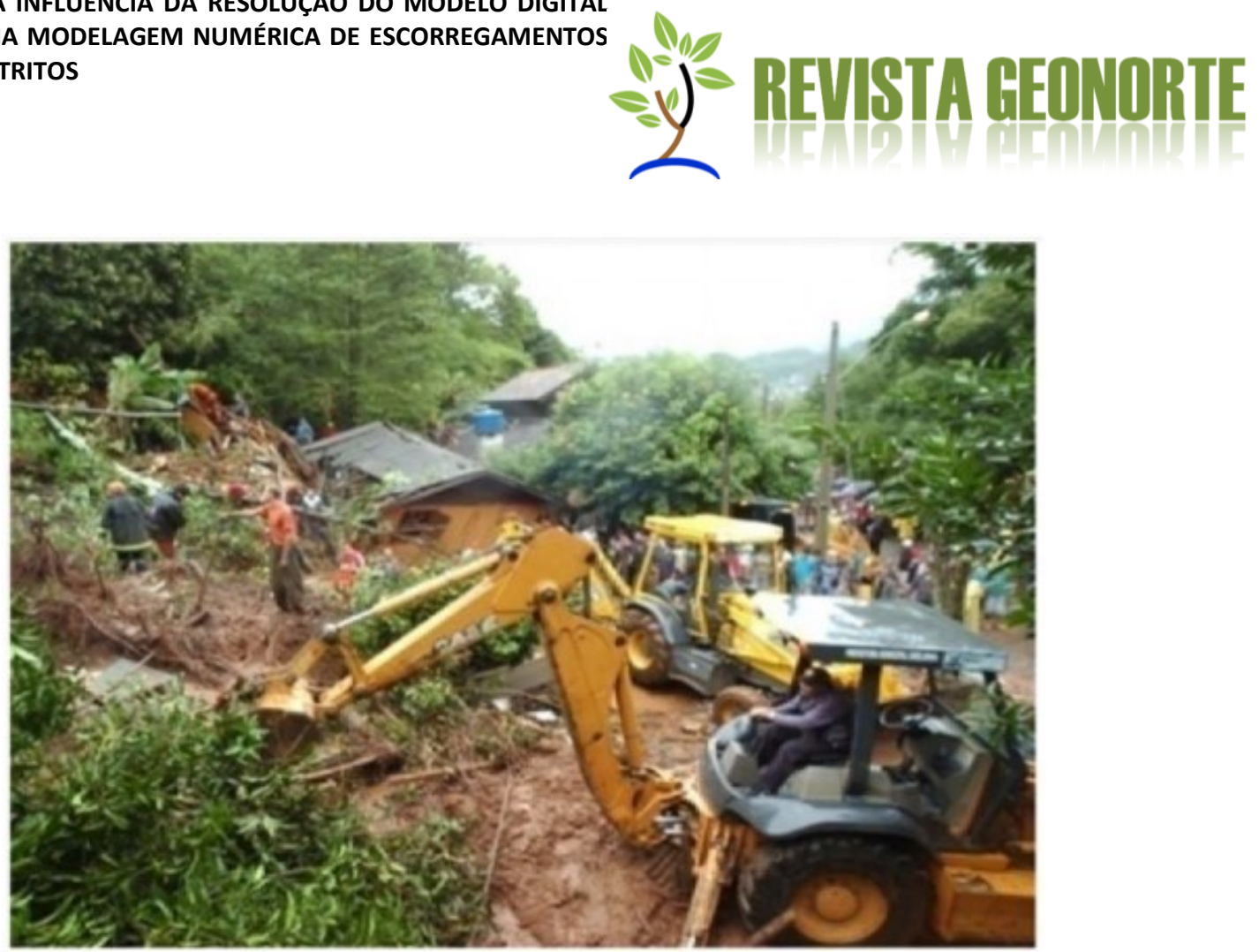

Figura 2. Cenário pós-evento em 2011 no bairro Saibreira do município de Igrejinha-RS. Fonte: CEPED-RS/UFRGS, (2014).

\section{Parâmetros do solo}

Sabe-se que as características e condições de saturação do solo são mecanismos reguladores da estabilidade de encostas. Dentre eles, quatro são os fatores essenciais para a verificação esquemática de uma possível ocorrência de um escorregamento: coesão do solo (Cs), ângulo de atrito interno do solo $(\varphi)$, massa específica do solo úmido $\left(\rho_{s}\right)$ e profundidade vertical do solo $(z)$.

O comportamento mecânico dos solos é influenciado por alguns aspectos que podem ser avaliados em termos de resistência ao cisalhamento. A resistência ao cisalhamento dos solos pode ser expressa pela equação de Coulomb:

$$
\tau=C s+\sigma \cdot \tan \varphi
$$

onde $\tau$ é a resistência ao cisalhamento; e $\sigma$ é a tensão normal ao plano de ruptura.

Os parâmetros de Cs e $\varphi$ podem ser obtidos através de ensaios de cisalhamento nas regiões de estudo, e sua caracterização é muito importante no mapeamento de áreas susceptíveis (MELO et al., 2021). Como o enfoque do presente estudo foi o efeito da qualidade do MDT, o presente trabalho adotou os valores médios de $C s, \varphi$ e z obtidos por Michel (2015) que estudou o município de São Vedelino (Tabela 1), 
AVALIAÇÃo DA INFLUÊNCIA DA RESOLUÇÃO DO MODELO DIGITAL DE TERRENO NA MODELAGEM NUMÉRICA DE ESCORREGAMENTOS E FLUXO DE DETRITOS

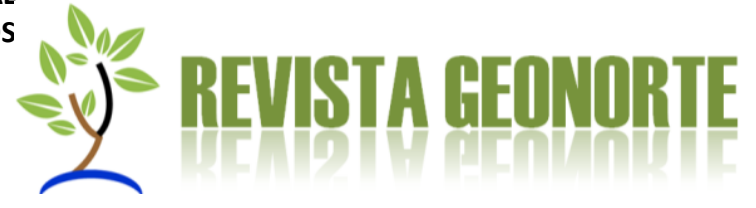

próximo ao de Igrejinha. Aqui se salienta que as características do solo são bastante similares entre esses dois municípios.

Tabela 1. Parâmetros de solo utilizados no SHALSTAB.

\begin{tabular}{lr}
\hline \multicolumn{1}{c}{ Parâmetro } & \multicolumn{1}{c}{ Valor } \\
\hline Coesão do solo $\left(c_{s}\right)$ & $7000 \mathrm{~N} \cdot \mathrm{m}^{-2}$ \\
Coesão das raízes $\left(c_{r}\right)$ & $0 \mathrm{~N} \cdot \mathrm{m}^{-2}$ \\
Profundidade do solo $(z)$ & $2 \mathrm{~m}$ \\
Ângulo de atrito $(\varphi)$ & $30^{\circ}$ \\
Carga proveniente da vegetação $(w)$ & $0 \mathrm{~kg} \cdot \mathrm{m}^{-2}$ \\
Massa específica do solo & $1720 \mathrm{~kg} \cdot \mathrm{m}^{-3}$ \\
úmido $\left(\rho_{s}\right)$ & \\
\hline
\end{tabular}

Fonte: MICHEL (2015).

\section{Modelos Digitais de Terreno}

Para testar a sensibilidade dos dois modelos (SHALSTAB e Kanako-2D), em relação ao tamanho de pixel, utilizou-se um MDT com resolução de 2,5 m, disponibilizado por CPRM (2015), durante o projeto Cartas de Suscetibilidade a Movimentos Gravitacionais de Massa e Inundações: 1:25.000. Este MDT foi gerado pela BRADAR por interferometria de dados de Radar de Abertura Sintética na banda $P$ (CPRM, 2015). Na banda $P$, a reflexão se dá ao nível do solo, permitindo a obtenção da altimetria do relevo (MDT) independentemente da existência de cobertura vegetal (GABOARDI e LÜBECK, 2016).

Juntamente com esse MDT disponibilizado pela CPRM, foram utilizados mais quatro MDTs que tiveram a qualidade do tamanho de pixel degradada, estes foram elaborados por Goerl et al. (2017) nas resoluções de $5 \mathrm{~m}, 10 \mathrm{~m}, 25 \mathrm{~m}$ e $50 \mathrm{~m}$, obtidos por reamostragem de pixels e através do algoritmo Bilinear, que determina o valor de uma nova célula com base na média ponderada pela distância dos quatro vizinhos mais próximos (ESRI, 2015).

Além dos parâmetros geotécnicos do solo como entrada do modelo foi necessário um mapa da área de contribuição em infinitas direções (D-inf). Para a obtenção desse mapa, utilizou-se no software QGIS a extensão Terrain Analysis Using Digital Elevation Models (TauDEM) proposto por Tarboton (1997) e Tarboton et al. (2015).

\section{SHALSTAB}

Para o mapeamento das áreas suscetíveis a escorregamentos, foi aplicado o modelo computacional SHALSTAB - Shallow Landsliding Stability Model proposto por Montgomery e Dietrich (1994). Trata-se de um modelo gratuito disponível na 
AVALIAÇÃo DA INFLUÊNCIA DA RESOLUÇÃO DO MODELO DIGITAL DE TERRENO NA MODELAGEM NUMÉRICA DE ESCORREGAMENTOS E FLUXO DE DETRITOS

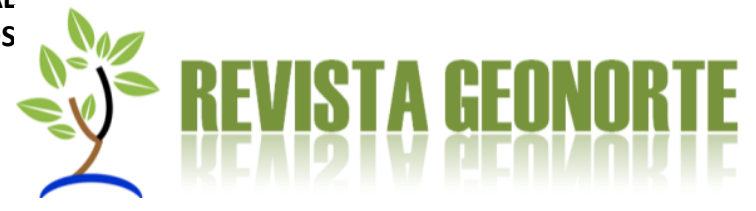

internet, de rápido processamento e que necessita de poucos dados de entrada do local de interesse. Esse modelo vem sendo comumente utilizado na elaboração de mapas de áreas susceptíveis a escorregamentos no Brasil (MELO e KOBIYAMA, 2018).

O SHALSTAB é um modelo que combina modelagem hidrológica uniforme de estado permanente e modelagem de estabilidade de encosta pelo método de taludes infinitos, para identificação de locais com predisposição a escorregamentos translacionais.

A combinação do modelo de encosta infinita e do modelo hidrológico de estado uniforme gera a seguinte equação:

$$
\frac{q}{T}=\frac{b}{a} \cdot \sin \theta \cdot\left\{\frac{\rho_{s}}{\rho_{w}} \cdot\left(1-\frac{\tan \theta}{\tan \varphi}\right)+\frac{c s+c r}{\cos ^{2} \theta \cdot \tan \varphi \cdot \rho_{w} \cdot g \cdot z}\right\}
$$

onde $q$ é a taxa de recarga uniforme $\left[\mathrm{m}^{\mathrm{d}} \mathrm{d}^{-1}\right] ; T$ é a transmissividade do solo $\left[\mathrm{m}^{2} \cdot \mathrm{d}^{-1}\right]$; $b$ é o comprimento do contorno $[\mathrm{m}] ; a$ é a área de contribuição a montante $\left[\mathrm{m}^{2}\right] ; \theta$ é a declividade da encosta [ $\left.{ }^{\circ}\right] ; \rho_{w}$ é a massa específica da água [kg.m ${ }^{-3}$; e $g$ é a aceleração da gravidade [m.s $\left.{ }^{-2}\right]$. A equação (2) descreve como o SHALSTAB classifica a estabilidade das encostas.

Os parâmetros $a$ e $b$ são obtidos do MDT, os parâmetros $\varphi$, $c$, e $\rho_{s}$ são obtidos pela amostragem do solo em campo ou obtidos na literatura e $z$ pode ser observado em campo ou na literatura. Os parâmetros $q$ e $T$ são variáveis hidrológicas e a razão entre eles retorna o grau de instabilidade para cada pixel da área de estudo. Segundo Dietrich e Montgomery (1998), os resultados do modelo são apresentados em escala logarítmica, pois essa razão apresenta valores muito pequenos (Tabela 2).

Tabela 2. Classes de classificação de estabilidade.

\begin{tabular}{cc}
\hline ID & CLASSES \\
\hline 1 & Incondicionalmente instável \\
2 & $\log q / T<-3,1$ \\
3 & $-3,1<\log q / T<-2,8$ \\
4 & $-2,8<\log q / T<-2,5$ \\
5 & $-2,5<\log q / T<-2,2$ \\
6 & $-2,2<\log q / T$ \\
7 & Incondicionalmente estável
\end{tabular}

Fonte: Adaptado de DIETRICH e MONTGOMERY (1998)

Michel et al. (2015) propuseram uma reclassificação dessas sete classes para facilitar o entendimento dos processos relacionados aos escorregamentos, 
AVALIAÇÃo DA INFLUÊNCIA DA RESOLUÇÃO DO MODELO DIGITAL DE TERRENO NA MODELAGEM NUMÉRICA DE ESCORREGAMENTOS E FLUXO DE DETRITOS

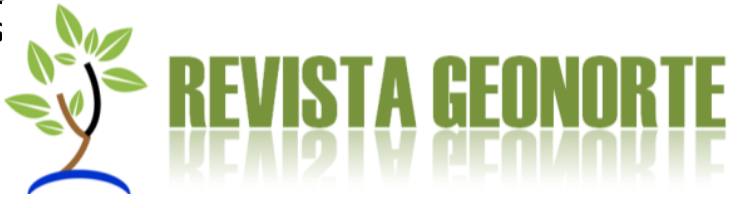

simplificando em quatro classes, sendo elas: incondicionalmente instável, incondicionalmente estável, instável e estável. As classes instável e estável são derivadas do agrupamento das cinco classes intermediárias apresentadas por Dietrich e Montgomery (1998).

A classe incondicionalmente instável é geralmente atribuída às áreas muito declivosas com baixa acumulação de solo, onde os parâmetros de resistência são superados.

$$
\tan \theta \geq \tan \varphi+\frac{c}{\cos ^{2} \theta \cdot \rho_{\mathrm{w}} \cdot g \cdot \mathrm{z}}
$$

A classe incondicionalmente estável pode ser identificada em áreas de baixa declividade sem condições para escorregamento, que apresentam parâmetros de resistência maiores ou iguais à declividade, mesmo sob intensas cargas hidráulicas.

$$
\tan \theta \geq \tan \varphi \cdot\left(1-\frac{\rho_{\mathrm{w}}}{\rho_{\mathrm{s}}}\right)+\frac{\mathrm{c}}{\cos ^{2} \theta \cdot \rho_{\mathrm{w}} \cdot \mathrm{g} \cdot \mathrm{z}}
$$

As classes instável e estável, derivadas do agrupamento das cinco classes intermediárias, estão diretamente relacionadas com a quantidade de água, classificadas conforme a razão do parâmetro $q / T$. Assim, com essa reclassificação, observa-se que um único valor de $q / T$ viabiliza a determinação do limiar de estabilidade e instabilidade.

Como acima mencionado, os valores dos parâmetros utilizados no SHALSTAB (Tabela 1) foram obtidos com base em Michel (2015). A ferramenta utilizada na simulação foi o ASA (Automatic SHALSTAB Analysis), elaborado por Sbroglia et al. (2017).

\section{Kanako 2D}

O Kanako-2D é um modelo numérico fisicamente embasado, desenvolvido por Nakatani et al. (2008), para fluxos de detritos pedregosos. Inicialmente o modelo foi desenhado para avaliar o efeito de diferentes tipos de barragens (grid, fenda ou fechada) na contenção de desastres relacionados a sedimentos, especialmente fluxo de detritos, tendo apenas análises unidimensionais. Já na versão bidimensional o Kanako-2D simula o fluxo a partir de sua entrada no canal na zona de iniciação com equações em 1-D e a propagação nas zonas de transporte e deposição do fluxo na 
AVALIAÇÃo DA INFLUÊNCIA DA RESOLUÇÃO DO MODELO DIGITAL DE TERRENO NA MODELAGEM NUMÉRICA DE ESCORREGAMENTOS E FLUXO DE DETRITOS

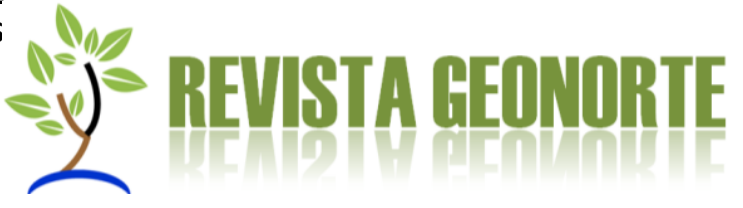

planície aluvial em 2-D (Figura 3). Além disso, o Kanako-2D é um modelo gratuito e que apresenta interface amigável para iniciantes em modelagem numérica e linguagem de programação.

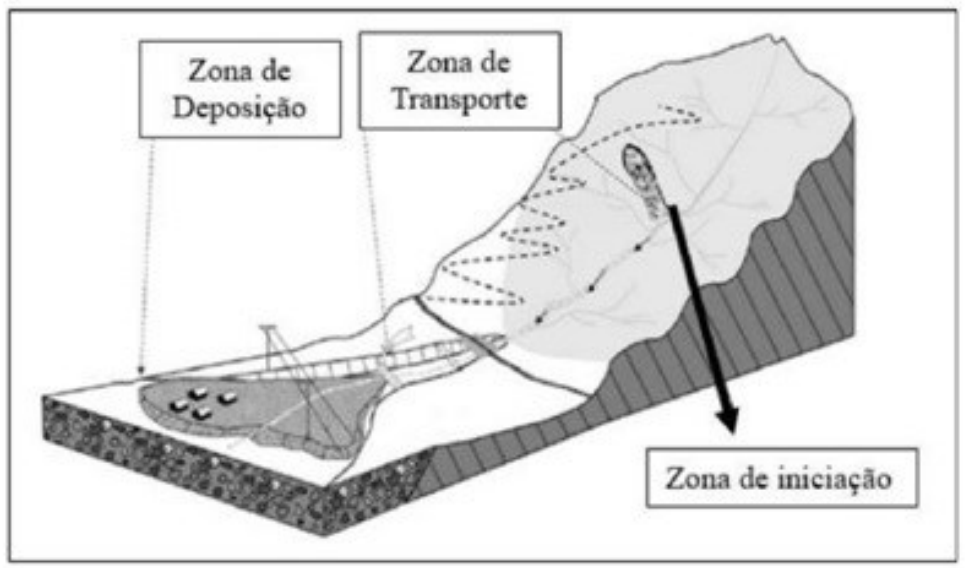

Figura 3. Zonas de um fluxo de detritos. Fonte: HUSSIN, (2011)

O modelo de fluído dilatante proposto por Bagnold (1954) foi adaptado por Takahashi (1977) para fluxos de detritos, no entanto essa aproximação era considerada muito simplificada e apresentava contradições. Então, Takahashi (1991), utilizando as considerações de Savage e Sayed (1984), reformulou a aproximação do modelo de fluido dilatante para a propagação de fluxos de detritos, resumidamente, nessa teoria, o mecanismo responsável por manter o fluxo são as forças repulsivas causadas pelas colisões entre as partículas. O Kanako-2D utiliza o modelo proposto por Takahashi (1991).

Há quatro equações fundamentais que define o modelo, a equação da continuidade para o volume total:

$$
\frac{\partial h}{\partial t}+\frac{\partial u h}{\partial x}+\frac{\partial v h}{\partial y}=i
$$

A equação da continuidade para determinação do fluxo na k-ésima posição da partícula $i$ :

$$
\frac{\partial C_{k} h}{\partial t}+\frac{\partial C_{k} h u}{\partial x}+\frac{\partial C_{k} h v}{\partial y}=i_{k} \cdot C^{*}
$$

A equação de conservação de momento nas direções $x$ e $y$ :

$$
\frac{\partial(u, v)}{\partial t}+u \frac{\partial(u, v)}{\partial x}+v \frac{\partial(u, v)}{\partial y}=g \cdot \sin \theta_{(x, y)}-\frac{\tau_{(x, y)}}{\rho_{f} h}
$$


AVALIAÇÃO DA INFLUÊNCIA DA RESOLUÇÃO DO MODELO DIGITAL DE TERRENO NA MODELAGEM NUMÉRICA DE ESCORREGAMENTOS E FLUXO DE DETRITOS

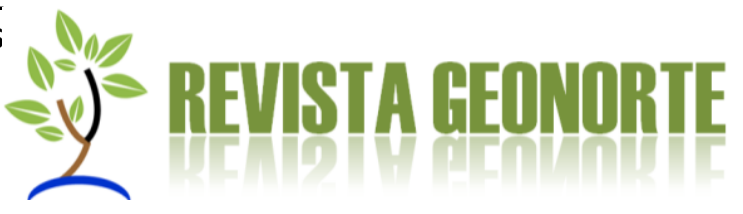

E a equação que avalia as deformações no leito:

$$
\frac{\partial z}{\partial \mathrm{t}}+\mathrm{i}=0
$$

onde $h$ é a altura do fluxo [m]; $u$ é a velocidade na direção $x\left[\mathrm{~m} . \mathrm{s}^{-1}\right] ; v$ é a velocidade na direção $y\left[{\mathrm{~m} . \mathrm{s}^{-1}}^{1}\right.$; $i$ é a taxa de deposição/erosão; $t$ é o tempo de simulação [s]; $C_{k}$ é a concentração de sedimentos por volume do fluxo na célula $k\left[\mathrm{~m}^{3} \cdot \mathrm{m}^{-3}\right] ; \theta_{x}$ e $\theta_{y}$ são as declividades nas direções $x$ e $y\left[{ }^{\circ}\right]$, respectivamente; $C^{*}$ é a concentração de sedimentos no leito móvel $\left[\mathrm{m}^{3} \cdot \mathrm{m}^{-3}\right]$; e $\tau_{x}$ e $\tau_{y}$ são as tensões de cisalhamento nas direções $x$ e $y[\mathrm{kPa}]$, respectivamente. Maiores detalhamentos sobre 0 equacionamento do Kanako-2D podem ser encontrados em Nakatani et al. (2008).

Para estabelecer o hidrograma de entrada de sedimentos foi utilizado o método de Whipple (1992), que adota um formato triangular, com tempo de ascensão menor que o tempo de recessão, o tempo de recessão adotado foi o dobro do tempo de ascensão. Além disso, para definir a vazão de pico foi utilizada a equação de Rickenmann (1999).

Os valores utilizados para a modelagem com o Kanako 2D (Tabela 3), com exceção do diâmetro das partículas que foi ajustado, foram propostos por Paixão e Kobiyama (2017) para o município de São Vedelino/RS que apresenta uma morfologia similar a área de estudo. Segundo Paixão et al. (2021b) que realizaram a análise se sensibilidade do Kanako-2D, três parâmetros (massa específica do leito móvel, diâmetro médio das partículas e ângulo de atrito interno) são mais sensíveis ao modelo.

Tabela 3. Parâmetros utilizados nas simulações com o Kanako-2D.

\begin{tabular}{lr}
\hline \multicolumn{1}{c}{ Parâmetro } & \multicolumn{1}{c}{ Valor } \\
\hline Massa específica do leito móvel & $2650 \mathrm{~kg} \cdot \mathrm{m}^{-3}$ \\
Massa específica da fase fluida & $1250 \mathrm{~kg} \cdot \mathrm{m}^{-3}$ \\
Concentração da camada móvel & $0,6 \mathrm{~m}^{3} \cdot \mathrm{m}^{-3}$ \\
Coeficiente da taxa de erosão & 0,0007 \\
Coeficiente da taxa de deposição & 0,05 \\
Diâmetro médio das partículas & $0,05 \mathrm{~m}$ \\
Ângulo de atrito interno & $30^{\circ}$ \\
Profundidade mínima do fluxo & $0,01 \mathrm{~m}$ \\
Profundidade mínima na frente do fluxo & $0,01 \mathrm{~m}$ \\
Concentração de sedimentos & $0,5 \mathrm{~m}^{-3} \cdot \mathrm{m}^{-3}$ \\
\hline \multicolumn{2}{c}{ Fonte: Adaptado de Paixão e Kobiyama $(2017)$}
\end{tabular}

\section{RESULTADOS E DISCUSSÕES}


AVALIAÇÃO DA INFLUÊNCIA DA RESOLUÇÃO DO MODELO DIGITAL DE TERRENO NA MODELAGEM NUMÉRICA DE ESCORREGAMENTOS E FLUXO DE DETRITOS

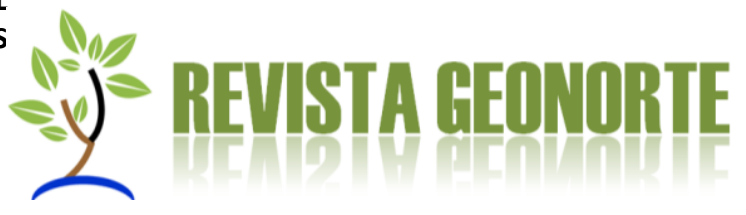

\section{Escorregamentos com o SHALSTAB}

Após a compilação dos parâmetros e a elaboração dos mapas de entrada do modelo, o SHALSTAB foi executado em um software de SIG (ArcGIS). A partir dos resultados, foi definida a classificação de estabilidade proposta por Michel et al. (2015), sendo ela dividida em quatro classes: incondicionalmente instável, incondicionalmente estável, instável e estável.

Seguindo essa classificação, definiu-se o limiar de instabilidade que divide as classes estável e instável como sendo o valor de log $q / T<-3,1$, que segundo Dietrich e Montgomery (1998) é o limiar da classe incondicionalmente instável e não saturado. $O$ resultado obtido para os 05 diferentes MDTs é demonstrado na Figura 4 , onde a cor vermelha apresenta os locais incondicionalmente instáveis (que, segundo Michel et al. (2015), é normalmente associada a paredões rochosos, onde é difícil haver acumulação de solo, e consequentemente, não ocorrem novos escorregamentos em situações normais), a cor laranja representa as áreas mais suscetíveis a escorregamentos, e a cor verde as áreas menos suscetíveis.
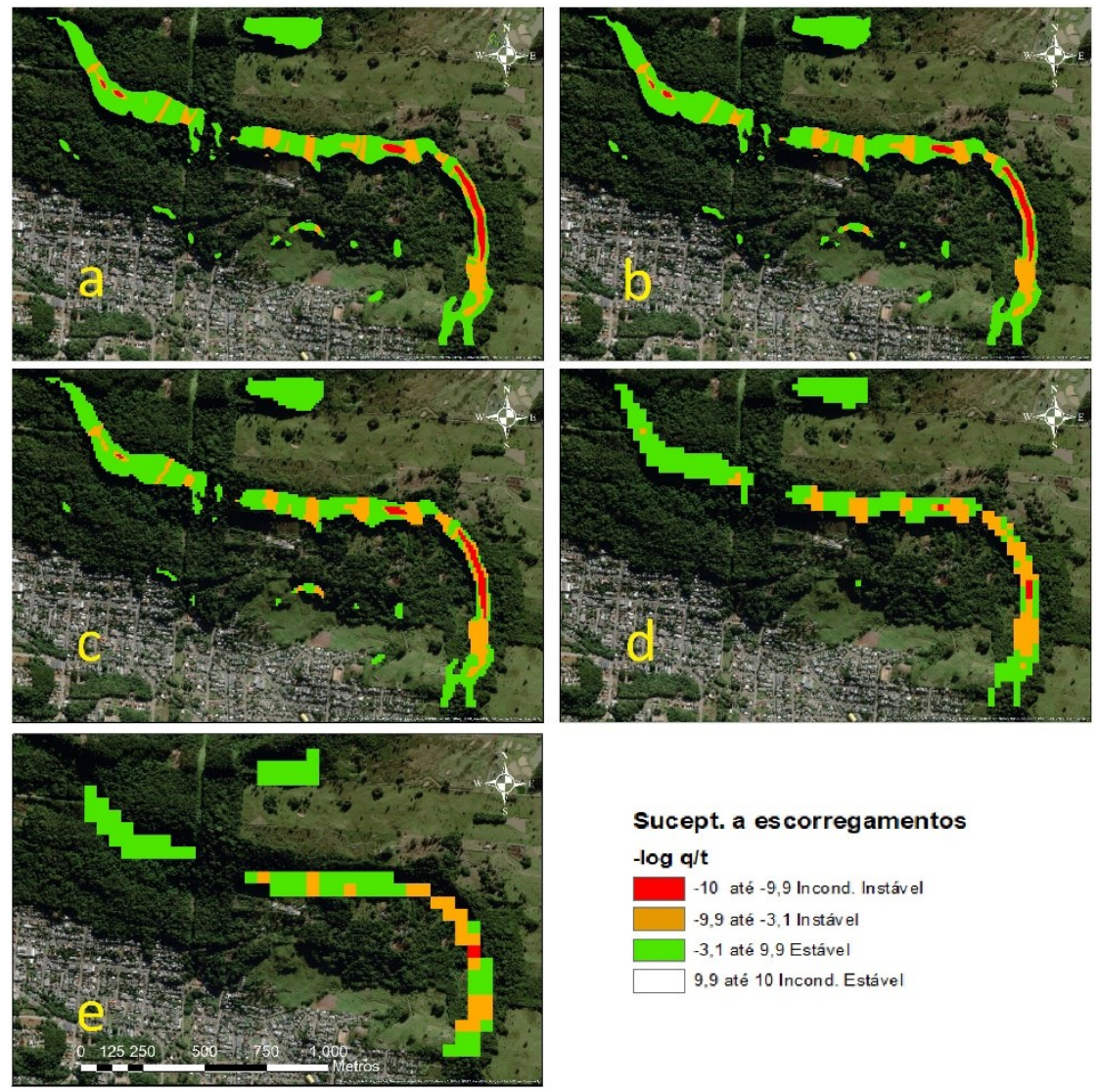

Sucept. a escorregamentos $-\log q / t$

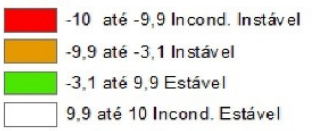


AVALIAÇÃo DA INFLUÊNCIA DA RESOLUÇÃO DO MODELO DIGITAL DE TERRENO NA MODELAGEM NUMÉRICA DE ESCORREGAMENTOS E FLUXO DE DETRITOS

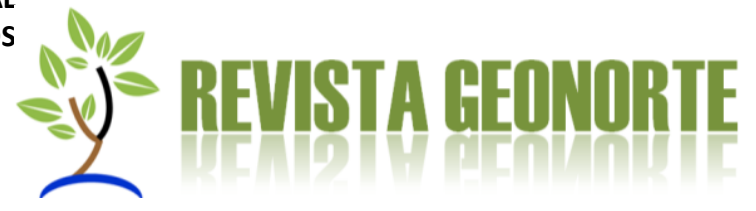

Figura 4. Resultado do SHALSTAB para as diferentes resoluções: (a) 2,5 m; (b) 5 m; (c) 10 m; (d) $25 \mathrm{~m}$; e (e) $50 \mathrm{~m}$. Fonte: Autores.

As áreas incondicionalmente estáveis, ou seja, áreas que, independentemente da quantidade de chuva, não ocasionarão escorregamentos, foram apresentadas na cor transparente. Em nenhuma das resoluções testadas foram encontradas residências nas áreas classificadas como incondicionalmente instáveis e instáveis. Isso pode implicar uma boa percepção dos moradores locais em relação a escorregamentos.

Com um tamanho de pixel pior, nota-se uma diminuição nas áreas classificadas como incondicionalmente instável e estável e um aumento nas áreas instáveis (Figura 5). Contudo essa variação não é muito nítida entre os modelos com maior qualidade no tamanho dos pixels $(2,5 \mathrm{~m}, 5 \mathrm{~m}$ e $10 \mathrm{~m})$, se tornando mais clara apenas nas resoluções de 25 e $50 \mathrm{~m}$ onde a classe incondicionalmente instável praticamente desapareceu. Vieira et al. (2017) encontrou resultados similares para o SHALSTAB, utilizando dois MDTs $(10 \times 10$ e $5 \times 5 \mathrm{~m})$ em uma área de 16,5 ha não foi notada uma melhora significativa no resultado do modelo com um pixel de 5 metros.

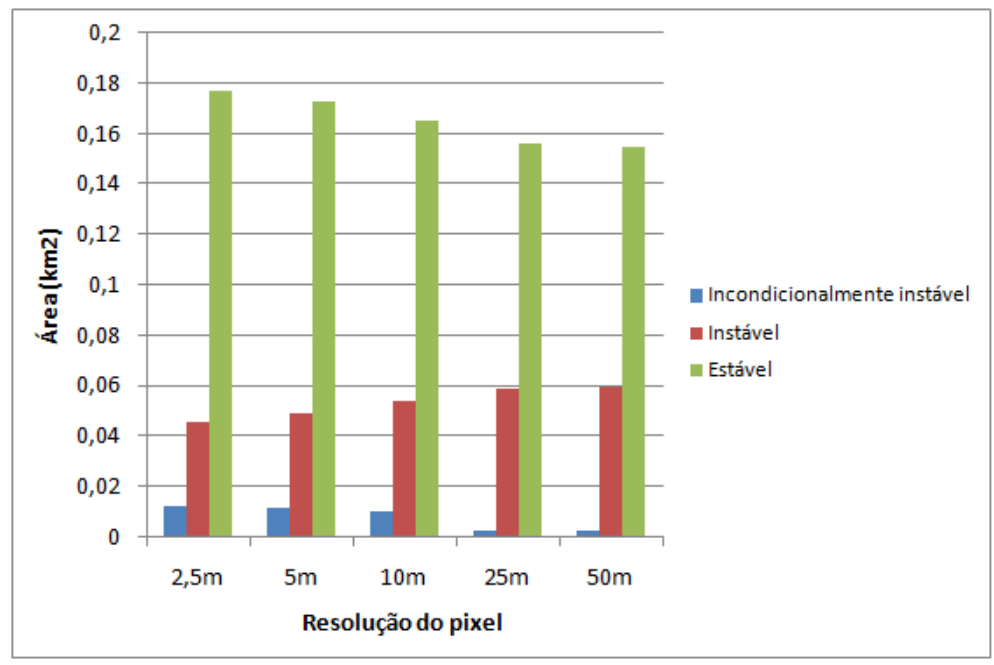

Figura 5. Relação entre as áreas de estabilidade e as diferentes resoluções. Fonte: Autores.

Com tamanhos de pixel maiores o contorno das áreas instáveis ficou grosseiro, o que levou a uma superestimação das áreas de instabilidade, isso dificulta o zoneamento para medidas preventivas. Nesses casos é necessária uma resolução mais detalhada, pelo menos com $10 \mathrm{~m}$, para que essas medidas sejam mais efetivas na escala do presente estudo. Schlögel et al. (2018) avaliaram os efeitos da resolução de 3 MDEs $(5 \times 5,10 \times 10$ e $25 \times 25 \mathrm{~m})$, com o objetivo de realizar um mapeamento de suscetibilidade na escala 1:10.000 utilizarando uma metodologia diferente (Modelo de Regressão Logística) juntamente com slope units, testando 
AVALIAÇÃO DA INFLUÊNCIA DA RESOLUÇÃO DO MODELO DIGITAL DE TERRENO NA MODELAGEM NUMÉRICA DE ESCORREGAMENTOS E FLUXO DE DETRITOS

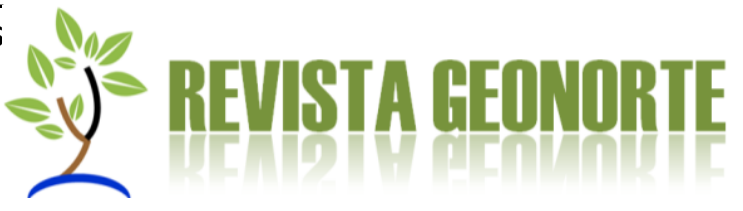

diversas combinações. No estudo deles, o modelo que apresentou os melhores resultados estatísticos foi o de 10 metros.

Claessens et al. (2005) utilizando modelos com pixels de 10, 25, 50 e $100 \mathrm{~m}$ em uma área de $12 \mathrm{~km}^{2}$, corroboraram que o efeito da resolução do MDT é mais pronunciado para as condições de contorno. Para as resoluções maiores, o efeito da suavização resulta em uma área menor sendo classificada como instável. Embora tenham realizado uma detalhada análise sobre tal efeito, os mesmos autores concluíram que não existe a resolução ideal e que a resolução sempre deve ser discutida.

Outros estudos (TRAN et al., 2017; ZHUO et al., 2020) demonstraram que modelos digitais mais detalhados nem sempre são a melhor escolha, pois podem superestimar as áreas instáveis, portanto o tamanho do pixel do modelo utilizado deve sempre levar em consideração a escala de estudo, as limitações do modelo utilizado e a finalidade do mapeamento gerado.

\section{Fluxos de detrito com o Kanako-2D}

Para a simulação com o Kanako-2D foi definida a zona de iniciação do fluxo de detritos, a partir do resultado obtido com o SHALSTAB. Assim, foi escolhida uma área classificada como instável - optou-se por não utilizar áreas incondicionalmente instáveis, pois estas costumam estar associadas a paredões rochosos, como já demonstrado em outros trabalhos como Fernandes et al. (2001) e Nonnemacher et al. (2019), onde o modelo (SHALSTAB) não admite a preservação de solo na encosta. A ocorrência desses paredões rochosos pode ser amplamente observada na área de estudo como demonstrado por CEPED-RS/UFRGS (2014), principalmente no bairro Viaduto (Figura 6).

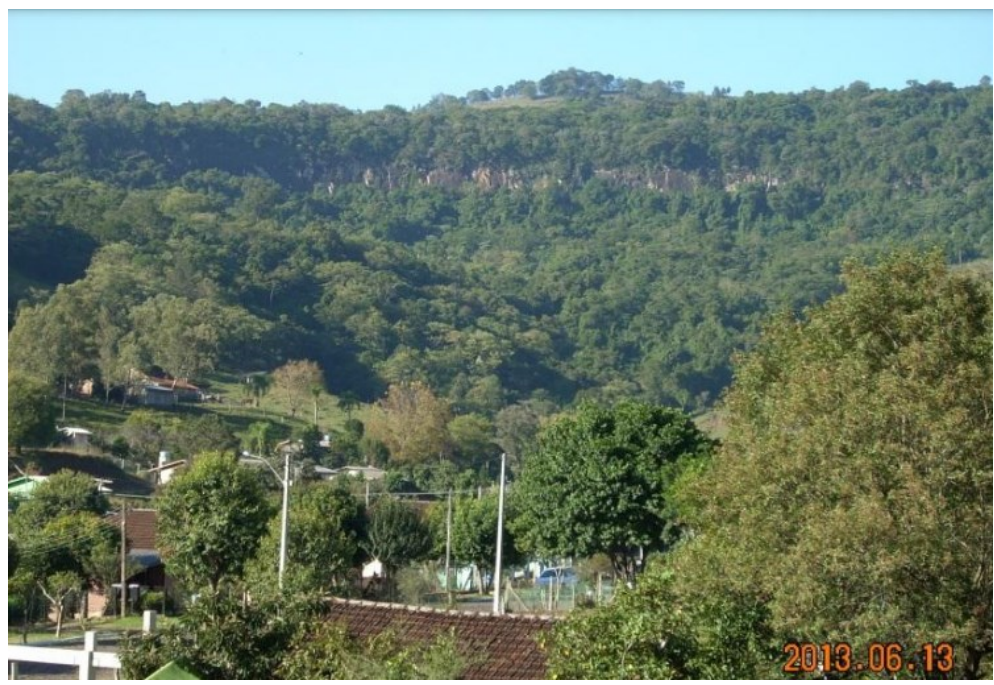


AVALIAÇÃO DA INFLUÊNCIA DA RESOLUÇÃO DO MODELO DIGITAL DE TERRENO NA MODELAGEM NUMÉRICA DE ESCORREGAMENTOS E FLUXO DE DETRITOS

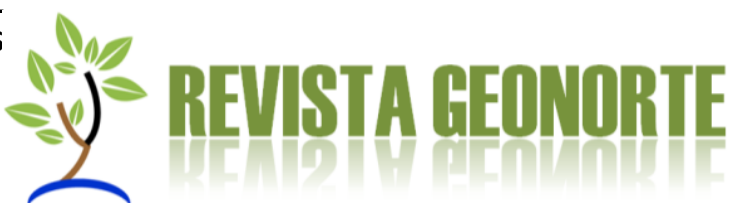

Figura 6. Paredões rochosos no bairro Viaduto. Fonte: CEPED-RS/UFRGS, (2014).

Com a área instável, e o valor de $2 \mathrm{~m}$ da profundidade de solo média no local, estimou-se o volume movimentado, o que permitiu determinar o hidrograma de entrada para a simulação de fluxo de detritos. A Figura 7 mostra o local escolhido como zona de iniciação (local destacado em azul). O mapa de instabilidade de encostas gerado com a resolução de $2,5 \mathrm{~m}$ foi utilizado para essa escolha.

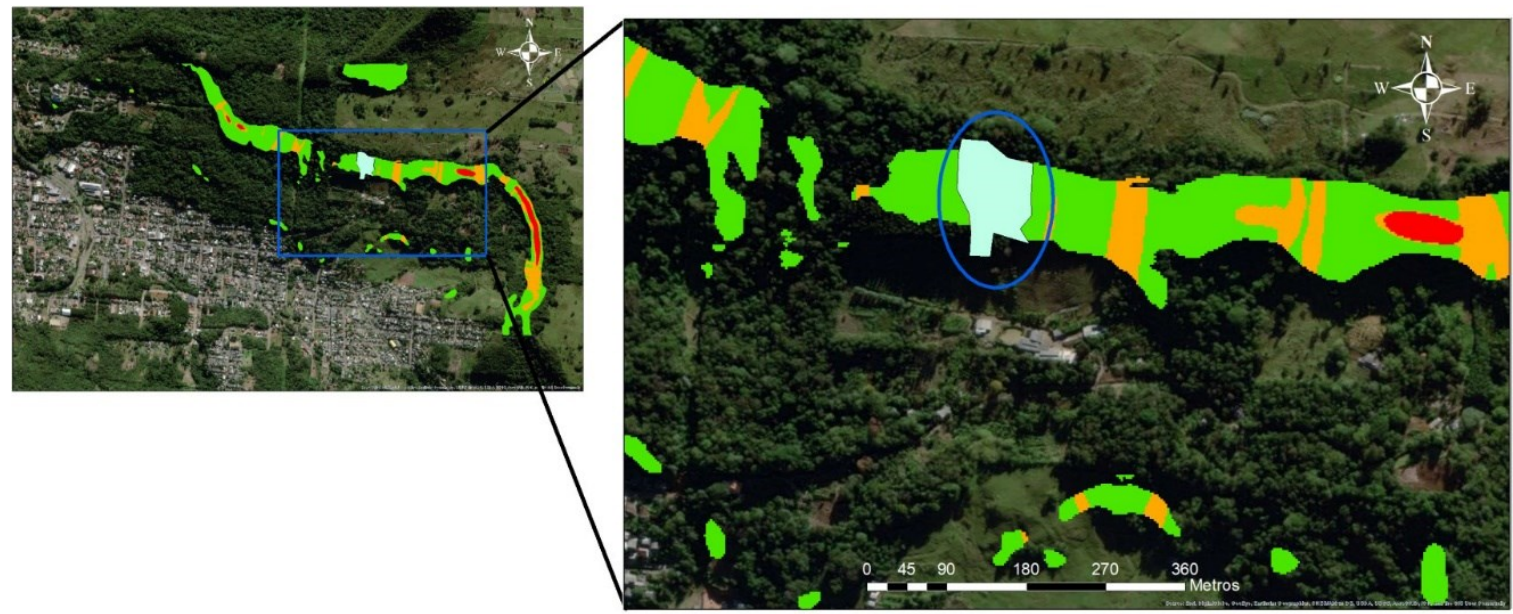

Figura 7. Local escolhido para a simulação com o Kanako-2D. Fonte: Autores.

Utilizando os dados da Tabela 3 e o hidrograma de entrada, o Kanako-2D foi aplicado com os MDTs de 2,5 m, $5 \mathrm{~m}, 10 \mathrm{~m}$ e $25 \mathrm{~m}$. Aqui salienta-se que o MDT de $50 \mathrm{~m}$ não foi utilizado pois a matriz de entrada no modelo ficava com poucos pixels, impossibilitando a simulação para a escala de estudo adotada. A Figura 8 demonstra os resultados, onde os locais com maior deposição são apresentados com a cor marrom escura. Observa-se que em um determinado momento o fluxo se dividiu em duas direções, sendo o fluxo da margem direita o que mais atinge residências. $\mathrm{Na}$ Figura 8, o valor positivo significa a deposição enquanto o negativo a erosão.

Devido ao método de obtenção do MDT original com resolução de 2,5 m (SAR), muitos ruídos provenientes da área urbana foram repassados ao modelo, isso gerou rugosidades que são mais evidentes nas áreas urbanas, fazendo com que o resultado da simulação apresente algumas áreas descontínuas. 

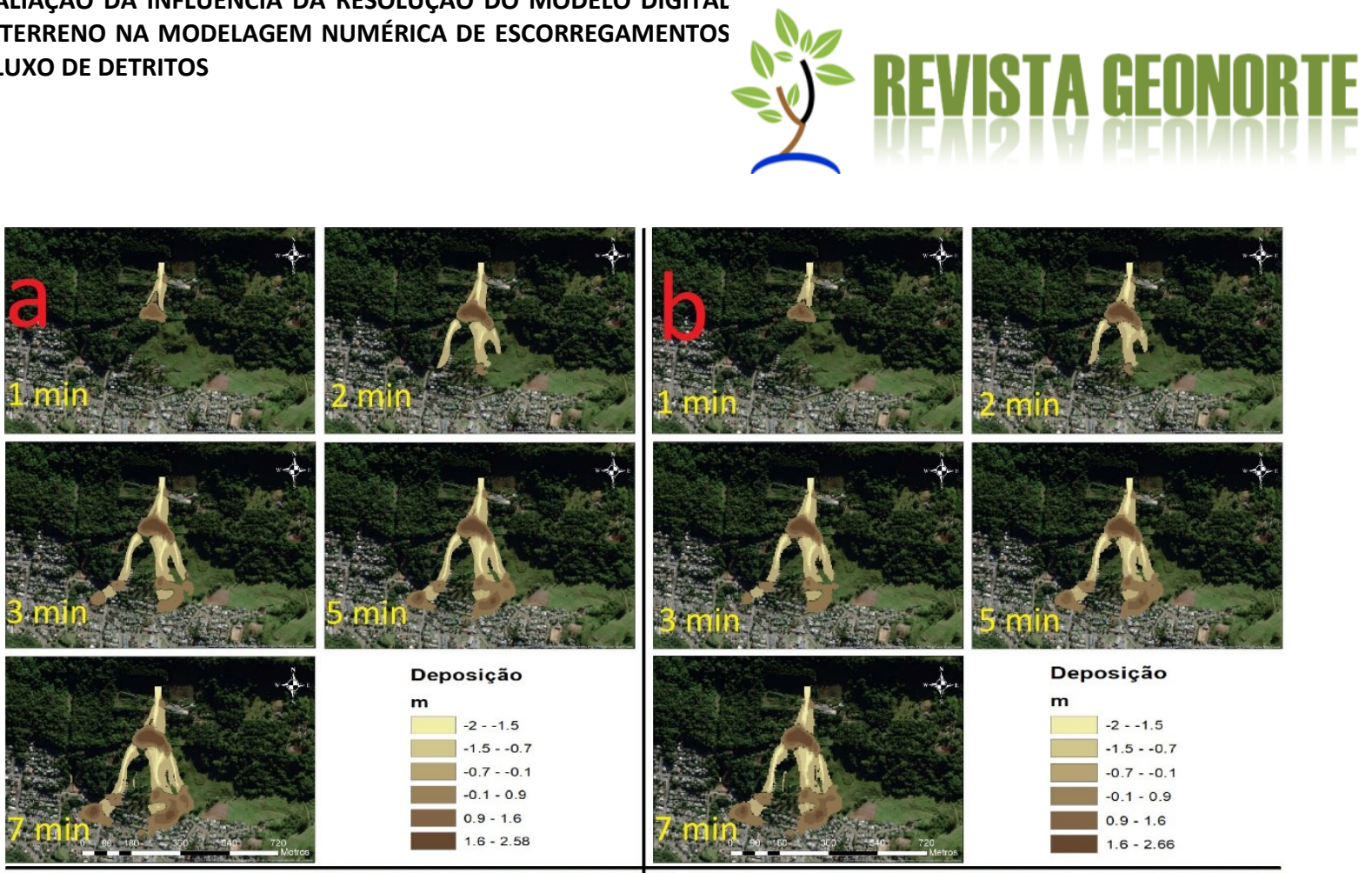

Deposição

m
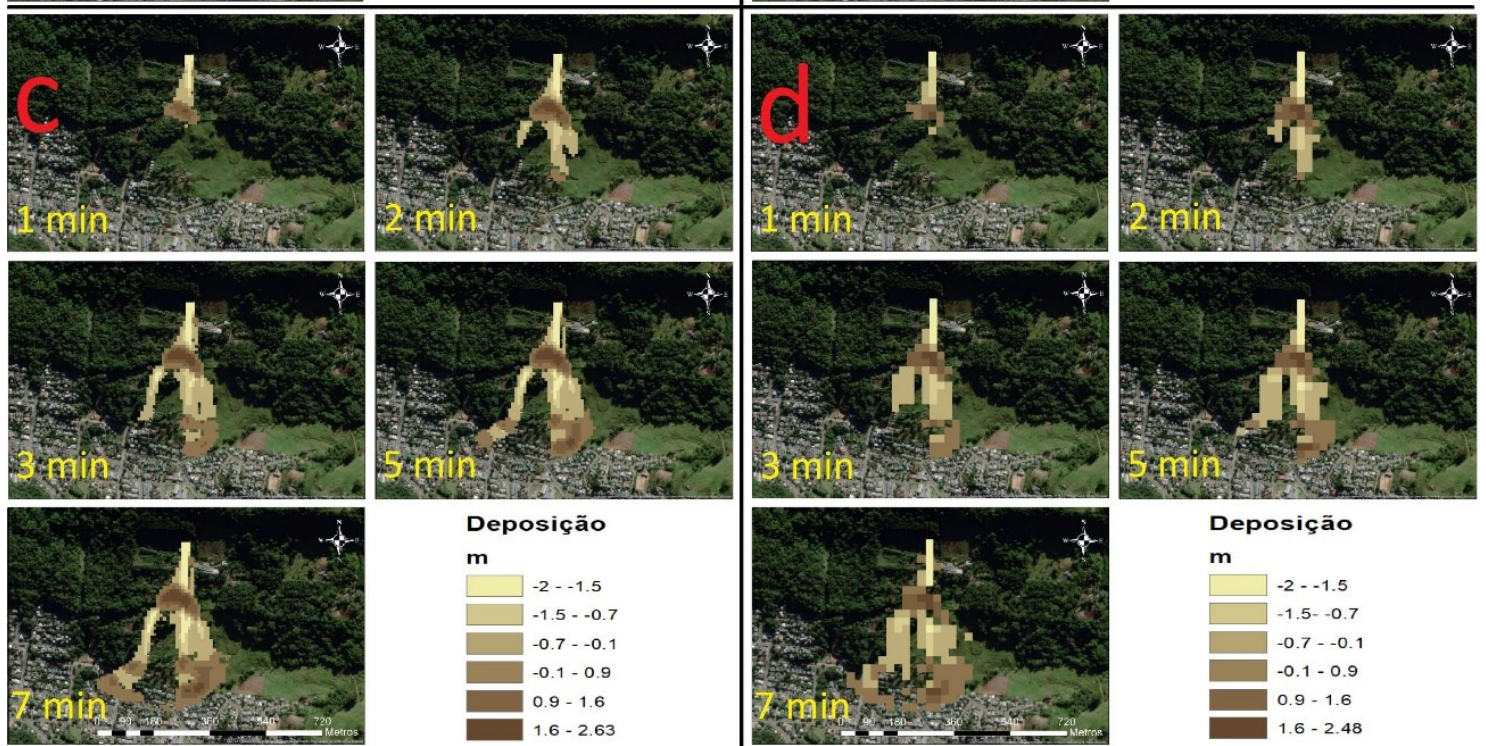

Figura 8. Resultado do Kanako-2D para as diferentes resoluções: (a) 2,5 m; (b) 5 m; (c) 10 m; e (d) $25 \mathrm{~m}$. Fonte: Autores.

Na Figura 8 observa-se uma variação na altura máxima de deposição, onde a mesma aumenta até o MDT de $10 \mathrm{~m}$ e no de $25 \mathrm{~m}$ diminui bruscamente, sendo a menor registrada nos MDTs utilizados. Isso se deve possivelmente ao menor detalhamento da topografia no MDT de pior qualidade, que não representa bem as pequenas variações do relevo. Uma consequência disso é que, ao utilizar um modelo digital com tamanho de pixel inadequado, existe uma chance de subestimar o volume de detritos e solo que atinge a zona urbana. 
AVALIAÇÃo DA INFLUÊNCIA DA RESOLUÇÃO DO MODELO DIGITAL DE TERRENO NA MODELAGEM NUMÉRICA DE ESCORREGAMENTOS E FLUXO DE DETRITOS

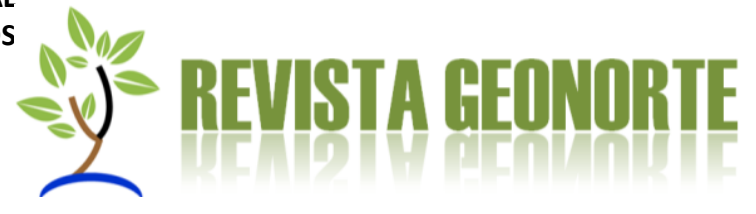

Isso demonstra a importância de um MDT com uma resolução adequada para elaborar um mapeamento de perigo de fluxo de detritos, pois nesse cenário onde um volume maior atinge as casas, os danos ao patrimônio e a perda de vidas humanas poderiam ser maiores. Da mesma forma que os resultados obtidos com SHALSTAB, apresentados na Figura 5, a área atingida nos resultados da simulação com o Kanako-2D nas resoluções com menores tamanho de pixel $(2,5 \mathrm{~m}, 5 \mathrm{~m}$, e $10 \mathrm{~m})$ apresenta pouca diferença se comparada com o resultado do modelo para a resolução de $25 \mathrm{~m}$.

No Brasil, o Kanako-2D está cada vez mais sendo aplicado, especialmente na Região Sul. Os resultados demonstram que o modelo possui bom desempenho e aplicabilidade para a realidade brasileira. Entretanto, são raros os trabalhos que avaliaram a influência da resolução nas simulções com o Kanako-2D. Syarifuddin et al. (2016) utilizaram três diferentes resoluções $(5 \times 5,30 \times 30$ e $90 \times 90 \mathrm{~m})$, em uma bacia de $58 \mathrm{~km}^{2}$ na Indonésia, concluindo que a resolução que trouxe melhores resultados foi a de $5 \times 5 \mathrm{~m}$, por representar melhor as variações do relevo que influenciam os fluxos laterais. No entanto, por meio da realização de mais estudos de caso, isso deve ser discutido mais profundamente, para diferentes escalas de estudo em diferentes locais.

A Tabela 4 mostra uma diminuição na velocidade de propagação no braço direito do fluxo nos modelos com maior tamanho de pixel, essa velocidade foi calculada com a relação da distância percorrida pelo fluxo e o tempo que o mesmo levou para atingir essa distância. Nas simulações com o MDT de $10 \mathrm{~m}$ e $25 \mathrm{~m}$ o fluxo demorou mais para se propagar pelo lado esquerdo.

Tabela 4. Velocidade média da margem direita do fluxo de detritos.

\begin{tabular}{cc}
\hline Resolução & $\begin{array}{c}\text { Velocidade } \\
\text { média }(\mathbf{k m} / \mathbf{h})\end{array}$ \\
\hline $2,5 \mathrm{~m}$ & 12,6 \\
$5 \mathrm{~m}$ & 12,3 \\
$10 \mathrm{~m}$ & 9,5 \\
$25 \mathrm{~m}$ & 8,1 \\
\hline
\end{tabular}

Fonte: Autores.

A velocidade média do fluxo varia na faixa de $8,1 \mathrm{~km} / \mathrm{h}$ a $12,6 \mathrm{~km} / \mathrm{h}$. Numericamente, pode-se dizer que esse valor não é muito rápido. Entretanto, as residências ficam perto das áreas de iniciação do fluxo de detritos, ou seja, o local de ocorrência de escorregamentos. Então, a chegada do fluxo na primeira casa é de 2 a 5 minutos dependendo da resolução do MDT adotada (Figura 8). Isso claramente alerta os 
AVALIAÇÃo DA INFLUÊNCIA DA RESOLUÇÃO DO MODELO DIGITAL DE TERRENO NA MODELAGEM NUMÉRICA DE ESCORREGAMENTOS E FLUXO DE DETRITOS

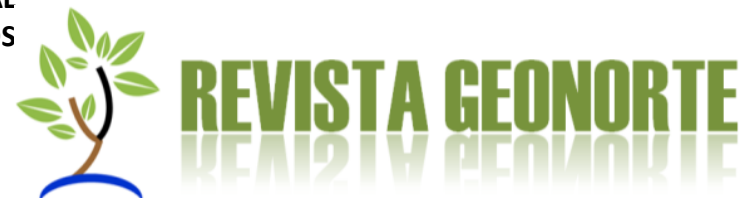

moradores que há muito pouco tempo para evacuar do local após o início de uma possível ocorrência.

A relação de casas atingidas foi realizada com o auxilio de imagens de satélite de alta resolução fornecidas pela ferramenta Basemap do software ArcGIS (ESRI). Observou-se que o número de residências atingidas diminuiu de acordo com o aumento do tamanho do pixel do MDT (Tabela 5). Isso alerta a Defesa Civil Municipal e também a população local para o fato de que, dependendo da resolução utilizada, pode-se subestimar o alcance - e também a velocidade e o volume - do fluxo e passar uma falsa sensação de segurança aos moradores.

Tabela 5. Estimativa de casas atingidas em cada cenário.

\begin{tabular}{cc}
\hline Resolução & Casas atingidas \\
\hline $2,5 \mathrm{~m}$ & 49 \\
$5 \mathrm{~m}$ & 48 \\
$10 \mathrm{~m}$ & 46 \\
$25 \mathrm{~m}$ & 45 \\
\hline
\end{tabular}

Fonte: Autores.

\section{CONSIDERAÇÕES FINAIS}

Os mapeamentos de áreas suscetíveis a escorregamentos e fluxos de detritos são ferramentas fundamentais no auxílio ao planejamento territorial e ambiental, e consequentemente à gestão de risco e de desastres associados a tais fenômenos naturais. Para discutir este tema ainda mais, o presente trabalho aplicou uma combinação de dois modelos (SHALSTAB e Kanako-2D) a uma das regiões problemáticas no município de Igrejinha/RS.

Para os tamanhos de pixel menores, isto é, $2,5 \mathrm{~m}, 5 \mathrm{~m}$ e $10 \mathrm{~m}$, foram classificadas quantidades maiores de redistribuição do solo, o que é atribuído à representação mais detalhada da paisagem. Observando os padrões espaciais de transporte de detritos e sedimentos, o tamanho da área afetada também aumenta com o aumento da qualidade do MDT.

Dessa forma, confirma-se que para maiores detalhes, se fazem necessários MDTs com pixels menores para mapeamento de áreas suscetíveis a movimentos de massa. No entanto são necessárias maiores investigações, testando a influência da resolução para diferentes escalas de estudo, a qualidade do mapa dependerá da escala de análise.

Os resultados obtidos com esses dois modelos, no entanto, não apresentaram grande diferença nos resultados com as simulações entre as resoluções de 2,5 m, 5 
AVALIAÇÃo DA INFLUÊNCIA DA RESOLUÇÃO DO MODELO DIGITAL DE TERRENO NA MODELAGEM NUMÉRICA DE ESCORREGAMENTOS E FLUXO DE DETRITOS

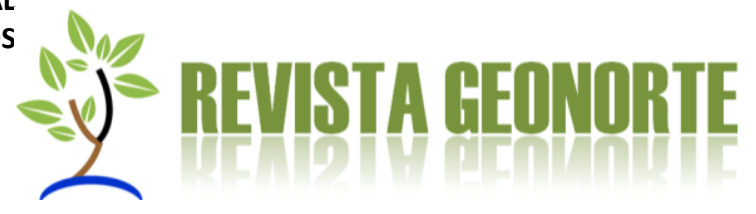

m e $10 \mathrm{~m}$. Isso implica que a resolução mínima para o MDT a fim de realizar simulações de escorregamentos e fluxo de detritos na escala do presente estudo (aproximadamente $3 \mathrm{~km}^{2}$ ) deve ser de pelo menos $10 \mathrm{~m}$. Entretanto, esse resultado foi obtido somente com o uso de dois modelos. Em trabalhos futuros, outros modelos e escalas de análise deverão ser testados, a fim de verificar e confirmar essa resolução mínima do MDT para avaliação de escorregamentos e fluxo de detritos.

\section{AGRADECIMENTOS}

Os autores agradecem ao CNPq pelas bolsas de estudo.

\section{REFERÊNCIAS}

AZAMBUJA, A. R. Diagnóstico da Defesa Civil no Município de Igrejinha. Igrejinha, $R S$. Defesa Civil, 2011.

BAGNOLD, R. A. Experiments on a gravity-free dispersion of large solid spheres in a Newtonian fluid under shear. Proc. R. Soc. London, v. 225, n. 1160, p. 49-63, 1954. DOI: https://doi.org/10.1098/rspa.1954.0186.

BAUM, R. L.; SAVAGE, W. Z.; GODT, J. W. TRIGRS: a Fortran program for transient rainfall infiltration and grid-based regional slope-stability analysis, version 2.0: U.S. Geological Survey Open-File Report, 2008-1159, 2008. 75 p.

BORGA, M.; DALLA FONTANA, G.; GREGORETTI, C.; MARCHI, L. Assessment of shallow landsliding by using a physically based model of hillslope stability.

Hydrological Process, v. 16, n. 14, p. 2833-2851, 2002. DOI:

https://doi.org/10.1002/hyp.1074.

BRUBACHER, J. P.; OLIVEIRA, G. G.; GUASSELLI, L. A. Identificação e análise de eventos extremos de precipitação na bacia hidrográfica do rio dos Sinos/RS. In: CONGRESSO BRASILEIRO SOBRE DESASTRES NATURAIS, 1. Rio Claro, 2012. Anais... 2012. p. 1-10, CD-ROM.

CEPED-RS/ UFRGS Elaboração de cartas geotécnicas de aptidão à urbanização frente aos desastres naturais no município de Igrejinha, $R S$ - relatório final. - Porto Alegre: CEPED-RS, 2014.

CLAESSENS, L.; HEUVELINK, G. B. M.; SCHOORL, J. M.; VELDKAMP, A. DEM resolution effects on shallow landslide hazard and soil redistribution modelling. Earth 
AVALIAÇÃO DA INFLUÊNCIA DA RESOLUÇÃO DO MODELO DIGITAL DE TERRENO NA MODELAGEM NUMÉRICA DE ESCORREGAMENTOS E FLUXO DE DETRITOS

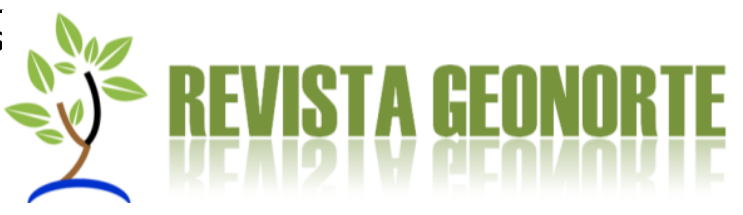

Surf. Process. Landforms, v. 30, n. 4, p. 461-477, 2005. DOI:

https://doi.org/10.1002/esp.1155

COELHO NETTO, A. L.; SATO, A. M.; AVELAR, A. S.; VIANNA, L. G. G.; ARAÚJO, I. S.; FERREIRA, D. L. C.; LIMA, P. H.; SILVA, A. P. A.; SILVA, R. P. The Extreme Landslide Disaster In Brazil. In: II WORLD LANDSLIDES FORUM - LANDSLIDES AND URBAN RISKS. Roma, 2011. Landslide Science and Practice. Volume 6: Risk Assessment, Management and Mitigation... Roma: Springer-Verlag, January 2011. p. 377-384.

CPRM - Serviço Geológico Brasileiro. Carta de suscetibilidade a movimentos gravitacionais de massa e inundação: município de Igrejinha - RS. Escala: 1:40.000. 2015.

DIETRICH, W. E.; MONTGOMERY, D. R. SHALSTAB: A digital terrain model for mapping shallow landslide potential. NCASI (National Council of the Paper Industry for Air and Stream Improvement), Technical Report, 1998. 29p.

ESRI. Cell size and resampling in analysis. 2015. Disponível em: <http://resources.arcgis.com/>. Acesso em: 12 dez. 2019.

FERNANDES, N. F.; GUIMARÃES, R. F.; GOMES, R. A. T.; VIEIRA, B. C.; MONTGOMERY, D. R.; GREENBERG, H. Condicionantes geomorfológicos dos deslizamentos nas encostas: avaliação de metodologias e aplicação de modelo de previsão de áreas susceptíveis. Revista Brasileira de Geomorfologia, v. 2, n. 1, p. 51-71, 2001.

GABOARDI, C.; LÜBECK D. Precisão altimétrica de modelo digital do terreno sob a vegetação obtido por interferometria de radar de abertura sintética de banda $P$. Revista Brasileira de Geografia, v. 61 n. 2, 2016. DOI: https://doi.org/10.21579/issn.2526-0375_2016_n2_p67-81

GOERL, R. F.; KOBIYAMA, M.; LOURENÇO, L. L.; GRANDO, A. Características gerais dos escorregamentos ocorridos em novembro de 2008 nos municípios de Brusque, Rio dos Cedros e Timbó - SC. In: XIII SIMPÓSIO BRASILEIRO DE GEOGRAFIA FÍSICA APLICADA, 2009, Viçosa. Anais... 2009. CD-ROM 16p.

GOERL, R. F.; MICHEL, G. P.; KOBIYAMA, M. Mapeamento de áreas susceptíveis a inundação com o modelo HAND e análise do seu desempenho em diferentes resoluções espaciais. Revista Brasileira de Cartografia, v. 69, n. 1, p.61-69, 2017.

GOMES, R. A. T.; GUIMARÃES, R. F.; CARVALHO JÚNIOR, O. A.; FERNANDES, N. F. Análise da influência da escala cartográfica no resultado de um modelo de previsão de áreas críticas a deslizamentos. Ciência e Natura, p. 269-286, 2004. 
AVALIAÇÃO DA INFLUÊNCIA DA RESOLUÇÃO DO MODELO DIGITAL DE TERRENO NA MODELAGEM NUMÉRICA DE ESCORREGAMENTOS E FLUXO DE DETRITOS

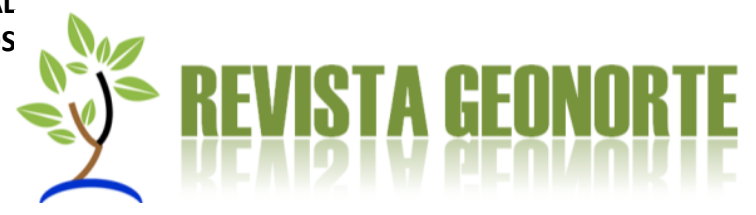

GOMES, R.A.T.; GUIMARÃES, R.F.; CARVALHO JÚNIOR, O.A.; FERNANDES, N.F.; AMARAL JÚNIOR, E.V. Combining spatial models for shallow landslides and debris-fl ows prediction. Remote Sensing, v. 13, p. 2219-2237, 2013.

GUIMARÃES, R. F.; CARVALHO JUNIOR, O. A.; GOMES, R. A. T.; FERNANDES, N. F. Comparative analysis of the SHALSTAB model from 1:10,000 and 1:50,000 scales. In: INTERNATIONAL GEOSCIENCE AND REMOTE SENSING SYMPOSIUM (IGARSS), Anchorage, AK, 2004, Proceedings... v.2, p. 1307-1309,

HUSSIN, H. Y. Probabilistic run-out modeling of a debris flow in Barcelonnette. Dissertação (Mestrado em Geo-information Science And Earth Observation) University of Twente, Enschede, The Netherlands. 2011. 107 p.

INSTITUTO BRASILEIRO DE GEOGRAFIA E ESTATÍSTICA - IBGE. Características da população e dos domicílios: resultados do universo. In: IBGE. Sidra: sistema IBGE de recuperação automática. Rio de Janeiro, 2011. Disponível em:<https://sidra.ibge.gov.br/home/ipca/brasil>. Acesso em: dez. 2019.

KOBIYAMA, M.; MICHEL, R. D. L. Debris-flow hazard investigation with Kanako-2D in a rural basin, Alto Feliz municipality (Brazil). In: 7th INTERNATIONAL CONFERENCE ON DEBRIS-FLOW HAZARDS MITIGATION. Golden, 2019. Proceedings... 2019. p.338-345.

KOBIYAMA, M.; GOERL, R. F.; FAN, F. M.; CORSEUIL, C. W.; MICHEL, G. P.; DULAC, V. F. Abordagem integrada para gerenciamento de desastres em região montanhosa com ênfase no fluxo de detritos. Revista Gestão \& Sustentabilidade Ambiental, v.7, n. esp, p.31-65, 2018. DOI: 10.19177/rgsa.v7e0201831-65

KOBIYAMA, M.; MICHEL, G. P.; GOERL, R. F. Proposal of debris flow disasters management in Brazil based on historical and legal aspects. International Journal of Erosion Control Engineering, v.11, n.3, p.85-93, 2019. DOI:

https://doi.org/10.13101/ijece.11.85

MARENGO, J.A. Mudanças climáticas, condições metereológicas extremas e eventos climáticos no Brasil. In: FBDS - Fundação Brasileira para o Desenvolvimento Sustentável (org.). Mudanças Climáticas e Eventos Extremos no Brasil. Rio de Janeiro - RJ: DaGema Comunicação, 2009. Cap. 1, p: (4-19)

MARTINS, P. A. Mapeamento das áreas suscetíveis a deslizamentos no perímetro urbano de Igrejinha - RS. Dissertação (Mestrado em Engenharia Civil), Escola de Engenharia, Universidade Federal do Rio Grande do Sul. Porto Alegre, 2013. 158 p.

MELO, C. M.; KOBIYAMA, M. Aplicação do modelo SHALSTAB no estudo de escorregamentos no Brasil: Revisão. Revista Brasileira de Geomorfologia, v.19, n.4, p.721-738, 2018. 
AVALIAÇÃo DA INFLUÊNCIA DA RESOLUÇÃO DO MODELO DIGITAL DE TERRENO NA MODELAGEM NUMÉRICA DE ESCORREGAMENTOS E FLUXO DE DETRITOS

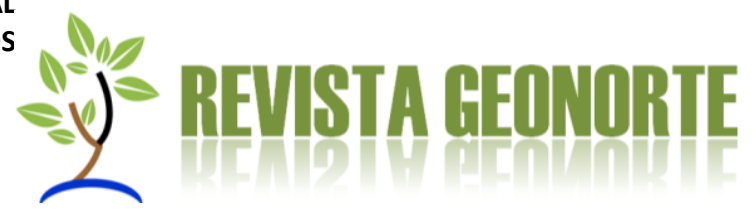

MELO, C.M.; KOBIYAMA, M.; MICHEL, G.P.; de BRITO, M.M. The relevance of geotechnical-unit characterization for landslide-susceptibility mapping with SHALSTAB. GeoHazards, v.2, p.383-397, 2021.

MICHEL, G. P. Estimativa da profundidade do solo e seu efeito na modelagem de escorregamentos. Tese (Doutorado em Recursos Hídricos e Saneamento Ambiental). Instituto de Pesquisas Hidráulicas, Universidade Federal do Rio Grande do Sul. Porto Alegre. 2015. 164 p.

MICHEL, G. P.; KOBIYAMA, M. Mapeamento de áreas susceptíveis a fluxos de detritos por meio de modelagem computacional. In Ladwig, N.I.; Schwalm, H. (org.) Planejamento e gestão territorial: Hidrografia e sustentabilidade. Florianópolis, 2016 p. 71-89.

MICHEL, G. P.; KOBIYAMA, M.; GOERL, R. F. Comparative analysis of SHALSTAB and SINMAP for landslide susceptibility mapping in the Cunha River basin, southern Brazil. Journal of Soils and Sediments, v. 14, p. 1266-1277, 2014.

MICHEL, G. P.; GOERL, R. F.; KOBIYAMA, M. Critical rainfall to trigger landslides in Cunha River basin, southern Brazil. Natural Hazards, v. 75, p. 2369-2384, 2015.

MICHEL, G.P.; KOBIYAMA, M.; GOERL, R.F.; ZANANDREA, F.; PAUL, L.R.; SCHWARZ, H.; CARDOSO, G.L. Efeitos da vegetação na modelagem de estabilidade de encostas na bacia hidrográfica do rio Cunha, Santa Catarina. Revista Brasileira de Geomorfologia, v.22, p.824-846, 2021a.

MICHEL, G.P.; SCHWARZ, H.; ABATTI, B.H.; PAUL, L.R.; SILVA, M.A.; ZANANDREA, F.; SALVADOR, C.G.; CENSI, G.; BIEHL, A.; KOBIYAMA, M. Relatório técnico dos desastres de dezembro de 2020 nos municípios de Presidente Getúlio, Ibirama e Rio do Sul - SC. Volume I. Porto Alegre: GPDEN/IPH/UFRGS, 2021b. 53 p.

MONTGOMERY, D. R.; DIETRICH, W. E. A physically-based model for topographic control on shallow landsliding. Water Resources Research, v. 30, p. 1153-1171, 1994

NAKATANI, K.; WADA, T.; SATOFUKA, Y.; MIZUYAMA, T. (2008). Development of "Kanako 2D (Ver.2.00)," a user-friendly one- and two-dimensional debris flow simulator equipped with a graphical user interface. International Journal of Erosion Control Engineering, v. 1, p. 62-72.

NONNEMACHER, L. C.; FRANCK, A. G.; KOBIYAMA, M. Avaliação preliminar da segurança de turistas na trilha do rio do Boi no Parque Nacional Aparadas da Serra. 
AVALIAÇÃO DA INFLUÊNCIA DA RESOLUÇÃO DO MODELO DIGITAL DE TERRENO NA MODELAGEM NUMÉRICA DE ESCORREGAMENTOS E FLUXO DE DETRITOS

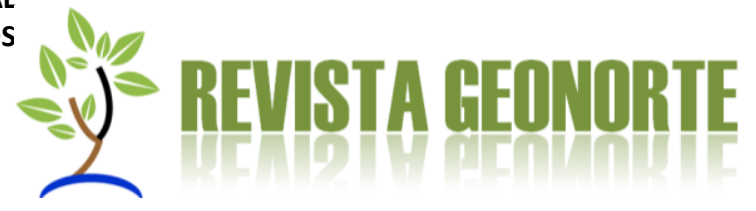

In: XXIII SIMPÓSIO BRASILEIRO DE RECURSOS HÍDRICOS, Foz do Iguaçu, 2019. Anais... 2019. 10p.

O'BRIEN, J. S.; JULIEN, P. Y.; FULLERTON, W. T. Two-dimensional water flood and mudflow simulation. Journal of Hydrological Engineering, v. 119, n. 2, p. 244-259, 1993.

PAIXÃO, M. A.; KOBIYAMA, M. Efeito do tamanho dos sedimentos sobre a área atingida por fluxos de detritos: Estudo de caso da bacia do arroio Böni, Serra Gaúcha. Ciência e Natura, v. 39, n. 2, p. 299-307, 2017.

PAIXÃO, M. A.; KABIYAMA, M.; ZAMBRANO, F. C.; MICHEL, G. P.; FAN, F. M. Lições sobre o Gerenciamento de Desastres Hidrológicos obtidas a partir da ocorrência em Rolante/RS. Revista Gestão \& Sustentabilidade Ambiental, v. 7, p. 251-267, 2018.

PAIXAO, M.A.; CORSEUIL, C. W.; KOBIYAMA, M.; GONZALEZ AVILA, I.; VANELLI, F.M.; OLIVEIRA, H.U.; VASCONCELLOS, S.M.; CAMPAGNOLO, K.; FAGUNDES, M.R. Occurrence of Multi-Disasters in the Mampituba River Basin, Southern Brazil, Duringthe COVID-19 Pandemic. International Journal of Erosion Control Engineering, v.13, n.4, p.84-92, 2021 a.

PAIXÃO, M.A.; KOBIYAMA, M.; FUJITA, M.; NAKATANI, K. Sensitivity analysis of debris flow simulations using Kanako-2D. International Journal of Erosion Control Engineering, v.14, n.1, p.1-11, $2021 \mathrm{~b}$.

RICKENMANN, D. Empirical Relationships for Debris Flows. Natural Hazards, v.19, n.1, p. 47-77, 1999.

ROSSATO, M. S. Os climas do Rio Grande do Sul: variabilidade, tendências e tipologia. Tese (Doutorado em Geografia). Universidade Federal do Rio Grande do Sul, Porto Alegre. 2011. 253 p.

SAVAGE, S. B.; SAYED, M. Stress developed by dry cohesionless granular materials sheared in an annular shear cell. J. Fluid Mech, v. 127, p. 453-472, 1984.

SBROGLIA, R. M.; PORATH, P. H. M.; HIGASHI, R. A. R.; OLIVEIRA, F. H. Mapeamento de Áreas Suscetíveis a Deslizamentos Translacionais com o Uso da Ferramenta ASA - Automatic Shalstab Analysis. In: XII CONFERÊNCIA brasileira SOBRE ESTABILIDADE DE ENCOSTAS, Florianópolis, 2017. Anais... 2017. 8p.

SCHLÖGEL R., MARCHESINI I., ALVIOLI M., REICHENBACH P., ROSSI M., MALET, J.-P. Optimizing landslide susceptibility zonation: Effects of DEM spatial resolution and slope unit delineation on logistic regression models.

Geomorphology. v. 301, p. 10-20, 2018. 
AVALIAÇÃo DA INFLUÊNCIA DA RESOLUÇÃO DO MODELO DIGITAL DE TERRENO NA MODELAGEM NUMÉRICA DE ESCORREGAMENTOS E FLUXO DE DETRITOS

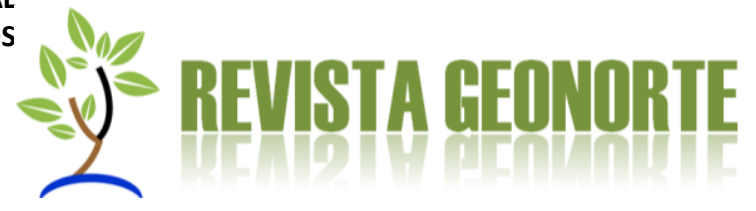

SILVA, R. P.; LIMA, P. H. M.; FACADIO, A. C.; COELHO NETTO, A. L. Condicionantes Geomorfológicos e Geológicos relacionados à deflagração de movimentos gravitacionais de massa: Bacia do Córrego Dantas, Nova Friburgo - RJ. In: XI SIMPÓSIO NACIONAL DE GEOMORFOLOGIA (SINAGEO), Paraná, 2016. Anais... 2016.

SYARIFUDDIN M., OISHI S., LEGONO D. Lahar flow simulation in merapi volcanic area by HyperKANAKO model. Journal of Japan Society of Civil Enginners, v. $72 \mathrm{n}$. 4, p. I_865-I_870, 2016.

TAKAHASHI, T. A mechanism of occurrence of mud-debris flows and their characteristics in motion. Annuals, DPRI, 20B-2 p. 405-435, 1977.

TAKAHASHI, T. Debris flow. (Monograph of IAHR). Balkema, Rotterdam. 1991. $165 p$.

TARBOTON, T. A new method for the determination of flow directions and upslope areas in grid digital elevation models. Water Resources Research, v. 33, n. 2, p.309319, 1997.

TARBOTON, D. G.; DASH, P.; SAZIB, N. TauDEM 5.3: Guide to Using the TauDEM Command Line Functions. 2015. 29 p.

TRAN, T. V.; LEE, G.; THU, T.; AN, H. Effect of Digital Elevation Model Resolution on Shallow Landslide Modeling Using TRIGRS. Natural Hazards Review. v. 18, n. 2. 04016011, 2017. DOI: 10.1061/(ASCE)NH.1527-6996.0000233.

TSUKAMOTO, Y.; MINEMATSU, H. Hydrogeomorphological characteristics of a zero-order basin. IAHS publication, v.165, p. 61-70, 1987.

VIEIRA, B. C.; MARTINS, T. D.; CORREA, A. C. B.; BATEIRA, C. V. M; Influência da resolução do MDT em modelagem de instabilidade de vertentes: análise preliminar. in: XVII Simpósio Brasileiro de Geografia Física Aplicada. Campinas - SP, 2017.

WHIPPLE, K. X. Predicting debris-flow runout and deposition on fans: the importance of the flow hydrograph. IAHS Publication, v.209, p. 337-345, 1992.

ZHUO C.; FEI Y.; WENXI F.; YUTIAN K.; HAOYUAN H. The influence of DEM spatial resolution on landslide susceptibility mapping in the Baxie River basin, NW China. Natural Hazards, v. 101, n. 3, p. 853-877. 2020. 